\title{
Emergency Medicine: Open
} Access

\section{Patient and Staff Safety Incidents and Near Misses in Out-Of-Hospital Emergency Care}

\author{
Mari Salminen-Tuomaala ${ }^{1^{*}}$, Päivi Leikkola ${ }^{2}$ and Eija Paavilainen ${ }^{3}$ \\ ${ }^{1}$ Seinäjoki University of Applied Sciences, School of Health Care and Social Work, Finland \\ ${ }^{2}$ Nursing Director, Seinäjoki Central Hospital, Finland
}

${ }^{3}$ Professor (Research Collegium 2011-2012). School of Health Sciences (Nursing Science) University of Tampere, Finland; South Ostrobothnia Hospital District, Seinäjoki, Finland

"Corresponding author: Mari Salminen-Tuomaala, PhD, Senior Lecturer, Seinäjoki University of Applied Sciences, School of Health Care and Social Work, Koskenalantie 17 Seinäjoki, Finland Tel: +350505739568; E-mail: mari.salminen-tuomaala@seamk.fi

Received date: June 25, 2014, Accepted date: September 09, 2014, Published date: September 16, 2014

Copyright: (c) 2014 Tuomaala MS, et al. This is an open-access article distributed under the terms of the Creative Commons Attribution License, which permits unrestricted use, distribution, and reproduction in any medium, provided the original author and source are credited.

\begin{abstract}
Objectives: The purpose of this qualitative study is to describe patient and staff safety incidents and near misses in out-of-hospital emergency care with the aim of providing new knowledge that can be useful in preventing and decreasing risks in emergency care. Research Methodology and setting: The data consisted of voluntary, anonymous reports collected online from emergency care staff in 2013 in one hospital district that serves a population of 200,000 in Finland. A total of 45 incident descriptions of adverse incidents, risks and near misses were accrued, all of which were analyzed using inductive content analysis.
\end{abstract}

Results: The results reveal that threats to patient safety are associated with the patient's psychological and physical status, medication, care equipment and context. In occupational safety of emergency care providers, the patient's mental ill-being and aggression, the context, care equipment and emergency driving constitute potential sources of risks.

Conclusion: As only a limited number of incidents were reported, staff should be encouraged to use the reporting system as an essential part of quality management in emergency services. More attention needs to be paid to assessing the overall emergency situation from the viewpoint of safety and the level and reliability of information before starting diagnostic procedures and treatment. Education and study of earlier safety incidents can help prevent risks.

\section{Introduction}

Patient and staff safety have internationally become an increasing concern in various healthcare sectors [1-4]. For example, approximately ten percent of patients in Europe are subject to some adverse event during their hospital care [3]. Up until today, little research has been conducted on patient and occupational safety in emergency care specifically. The knowledge gap is even wider as regards out-of-hospital emergency care. Much of emergency care is started in pre-hospital settings and not all patients even need to be taken to hospital. Very often, emergency care can be competently delivered in the patient's home $[5,6]$ or other location, using a "stay and play" approach.

To summarize some of the existing research: A study conducted on adverse events and near misses in the United Kingdom revealed that patient safety events had most often involved medication errors, poor communication and equipment malfunction, defect or misuse [7]. Studies on medication errors have shown that risks were caused by overdosing or administering a wrong drug $[8,9]$. Further studies reveal that patient safety is associated with staff competence [10-12]. Besides clinical competence, emergency care providers need situational sensitivity and problem-solving skills. They need to be able to anticipate risks and safety incidents and to identify near miss situations [13-15]. Even deciding whether to treat a patient at home can involve a risk [6,16-19]. The patient's physical condition is usually carefully assessed and well documented, but more attention needs to be paid to documenting the patient's psychological status and effects of interventions taken [20]. Inexperienced recent graduates require support from more experienced colleagues, especially in unanticipated situations that call for brisk decision-making and action. Young staff members may feel pressured to act fast, while simultaneously feeling insecure about their assessment and decision-making competence. Not yet able to assess the overall situation, they tend to focus on detail $[8,21]$.

In occupational safety, adverse events and near misses have been shown to be associated with equipment malfunction and with risks caused by circumstances or violence [7]. Unanticipated, rapidly changing situations and lacking information of patients' medical history increase the risk of safety incidents [8]. Misunderstandings and other disruptions in the flow of information have often been found to contribute to adverse events [22-24]. All relevant background information should therefore be readily available electronically [25].

It is clear that systematic action is required to recognize risks and to prevent human error [26,27]. It may be added in this context that a conceptual model has been proposed [28], suggesting that the safety and quality of patient care, as well as the occupational safety of care providers, can be assessed in terms of structure, process or outcome of care. This perspective could be applied to out-of-hospital emergency care as well. 
A word on terminology: This study uses the term safety incident to refer to unintended or unexpected (adverse) events which led or could have led to some harm for either patients or emergency care providers. The term near miss is used for events that came very close to harming patients or professionals.

\section{Objectives}

In an attempt to decrease the knowledge gap regarding patient and occupational safety in out-of-hospital emergency care, this paper describes patient and staff safety incidents and near misses in out-ofhospital settings in one hospital district in Finland. The study aims at providing new knowledge that can be useful in preventing and decreasing risks in emergency care.

\section{The research questions are:}

What kind of situations occurs in emergency care that jeopardizes patient safety?

What kind of situations occurs in emergency care that jeopardizes the action and safety of emergency care staff?

\section{Methods}

\subsection{Data collection}

Data for this qualitative research were collected in the first ten months of the year 2013 in one hospital district that serves approximately 200,000 inhabitants in Finland. The material was obtained from a Web-based Reporting System called HaiPro. This nationwide reporting system, launched in 2005, was designed to collect health care providers' voluntary, anonymous descriptions of risks, safety incidents and near misses in health services. The system is based on voluntary, anonymous staff reporting of near misses and adverse events in both patient care and occupational safety. The system contains a single question, requesting potential respondents to describe a safety incident and its threatening elements in their own words. The idea is to encourage health professionals to study the causes and onset mechanisms of adverse events and near misses and to look for preventive action [29]. Learning to identify near misses can help staff to avoid potentially risky situations and change their action and behavior [30]. Voluntary, anonymous reporting allows dealing with safety issues without public guilt and shame [22-24,31].

The number of incident descriptions obtained in the target population (one hospital district with 200,000 inhabitants) between January and November in 2013 was 45 . All these descriptions were included in this study retrospectively.

\subsection{Data analysis}

Data were analyzed using inductive content analysis. A statement expressed in a word, cause or sentence - was selected as the unit to be analyzed. Data were reduced by coding them by research task. Similarities and differences were identified and statements combined to produce sub-categories. Sub-categories with similar contents were combined to yield main categories. Reliability of the analysis was improved by including authentic extracts from the HaiPro Reporting System [32].

\section{Results}

The results section is based on a qualitative analysis of the all the incident descriptions obtained during 10 months in 2013 through the voluntary online HaiPro Reporting System in a hospital district that serves a population of 200,000 . The results section in has been divided into two parts, the first of which deals with patient safety. The second part describes adverse incidents and risk factors in the work of emergency care staff.

\subsection{Risks to patient safety}

In this study, risks to patient safety in out-of-hospital emergency care were associated with the patient's psychological and physical condition, medication, equipment and context, as shown in figure 1. It was also revealed that patient safety can be compromised by poor communication or reporting. None of the factors predominated.

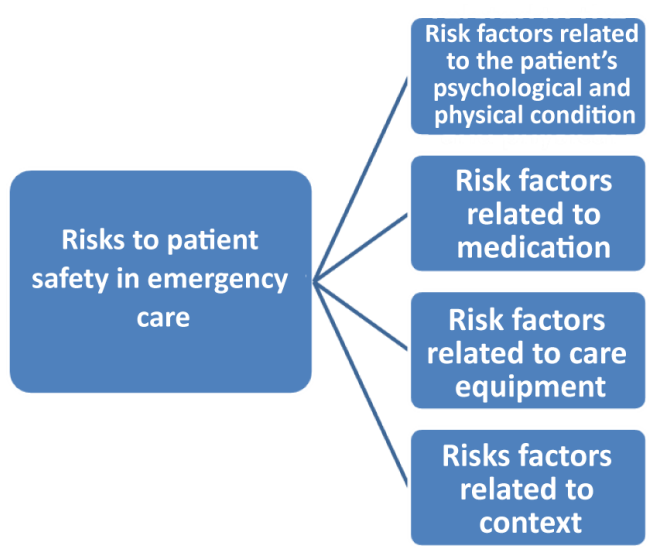

Figure 1: Risks to patient safety in emergency care

Risk factors related to the patient's psychological and physical condition:Safety incidents and near misses in emergency can be associated with patients' memory disorders, confusion, physical frailty or mental health problems. In the following example, the combined poor physical condition of a stroke patient and staff negligence resulted in an adverse incident.

A patient had been taken to the ward by ambulance. They had left him sitting alone on the edge of the bed. The ward staff had not been properly informed of the patient's condition. The patient fell and hit his head on the floor.

Risk factors related to medication: Even when immediate medication is required, calculating the correct dose should not be compromised. This study showed that medication errors were a potential source of risk in emergency care. As in the example below, errors may be caused by lack of experience. Novice staff members do not always have a conception of what constitutes a normal dose. Unclear division of duties was another factor that resulted in problems in the care providers' descriptions, for example when ambulance crew stayed in health centre to assist staff there.

My colleague gave a patient $10 \mathrm{mg}$ of Diazepam IV, instead of $2 \mathrm{mg}$. She must have misheard the doctor's orders during consultation, and 
she had no idea of a normal dosage yet. The patient stopped breathing and we had to bag him.

We were in the health centre helping out and there was a patient suffering from chest pain. Because of his general condition, we took an ECG and put him on a drip. The doctor ordered him Nitro infusion and I thought that the health centre nurse would go and dilute it. This did not happen for some reason and the doctor started to demand it from me at full voice. So I made a thinking error in a hurry and withdrew three ampoules into a syringe. We did not notice the mistake immediately, but I started to wonder as the patient's blood pressure went down. The patient's life was not at risk, but it was a near miss. The division of duties was not clear, who should do what. The medication area was restless and the doctor interfered by shouting and rushing us.

Risk factors related to care equipment: Equipment malfunction, whether it concerns communication tools or devices used to measure vital signs, is another potential source of risk, as shown in this study, too. For example, devices used to measure blood sugar or blood pressure may occasionally give wrong readings. Experienced staff knows how to reduce risks by combining and comparing readings and patient observation, as in the following description written by a care provider:

We were taking a patient's blood sugar. First, it was 32.5. After a minute, however, we measured it again and it was 7.2. We tried once more with the patient's own device and got the result 12.0. The patient was poorly, faint and tired. Had we not measured again, the patient would have been at risk, because we would have given him a large dosage of Novorapid.

The mobile of our unit got out of whack. We were unable to contact anyone by telephone. We needed to call and consult a doctor in the central hospital, but we could not reach any number. The phone asked for an update of the software, which we could not perform, not being able to contact the server.

Risk factors related to the context: Out-of-hospital care can take place in any context. Risks may be caused by the environment, weather conditions or people present in the situation. The patient may be waiting for help in difficult access locations; on a roof, in the street, in water or on a scene with a great number of people. Access to the scene may be complicated by weather or traffic conditions. In cold weather, patients waiting outdoors are subject to the risk of hypothermia.

A patient had fallen into an AIV fodder silo. We had to wait for assistance to be able to lift him up. The patient was conscious but unable to move his limbs.

Distressed people on the scene may affect the emergency care team's possibilities to help the patient. Those present may have their own, different views of how the patient should be treated.

It was difficult to interview the patient, because the family members kept pressing us to take him to hospital. They were anxious and did not understand when we said that the situation needed to be assessed first. They kept shouting and jumping about around us.

\subsection{Risks to occupational safety in emergency care}

Figure 2 shows that risk factors in the occupational safety of emergency care staff were found to be associated with patients' psychological ill-being and aggression, the context, equipment and emergency driving. The first factor mentioned, patients' psychological ill-being and aggression stood out as the most prominent factor.

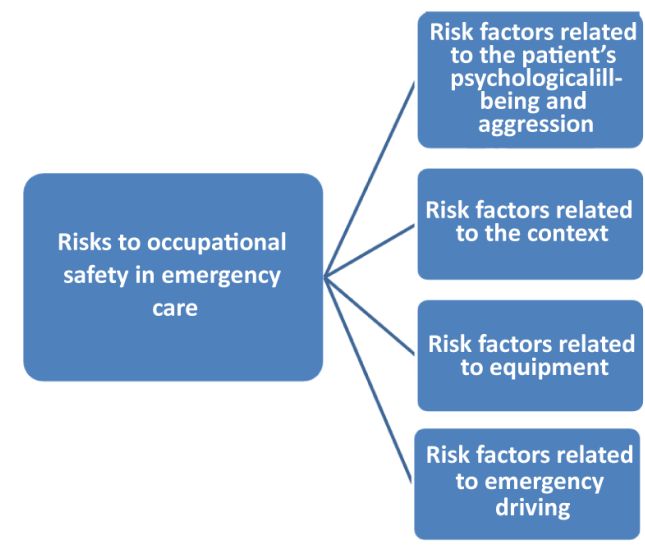

Figure 2: Risks to occupational safety in emergency care

Risk factors related to the patient's psychological ill-being and aggression: The following examples illustrate how the patient's psychological ill-being and aggression may put the staff s occupational safety at risk. In most reports within the HaiPro system such incidents were associated with patients' heavy use of alcohol or mental health problems. Combined use of alcohol and drugs may lead to verbal or physical aggression. Acutely changing situations and patients' unexpected behavior endangers the occupational safety of emergency care staff.

A patient had called the emergency centre complaining of back pain. He had consumed a great deal of alcohol during the day. When the ambulance got there, the patient refused to answer any questions about the care. They tried everything to get him into the vehicle, but he would not co-operate. The patient's behavior became aggressive. His speech was aggressive, too. He tried to hit one staff member. $\mathrm{He}$ threw a lot of stones, hitting the front of the ambulance, while the paramedics had to take refuge in the ambulance.

I was about to remove the blood pressure cuff from a drunken man, when he hit me in the nose.

Patients' restlessness and aggression may also be due to side effects of drugs. Sometimes patients express discontent with treatment alternatives or take it for granted that the ambulance will take them to hospital. The patient in the following description found it difficult to accept that his condition did not require ambulance transport.

A patient called the emergency centre because of leg pain. He told that he had a severe pain in the hip and that his own pain medication was not sufficient at all. The pain in the leg and the injury were an old complaint, the patient was still able to take brisk steps. The patient demanded that the ambulance crew should take him to hospital and that they should come and tell the doctor how to treat the leg. He was told that there was no need for ambulance transport but that a taxi might be called to take him to see a doctor. The patient got angry, rushed into the kitchen to get a big knife, using it to threaten the care providers and saying that he would cut off his leg if he was not taken to hospital. He threw off the knife into the wall and continued verbal aggressive behavior. The patient had decided to get into hospital by ambulance and he did not agree with the facts concerning his 
admission. He may have had withdrawal symptoms after discontinuation of Tramal that may have caused this outburst.

Use of illicit drugs can result in aggressive behavior. Several drug users may be gathered in a location when the ambulance arrives, which adds to the risk. It is often necessary to seek assistance from the police.

A patient had called an ambulance because he was unable to stand. The ambulance arrived and they found the house door locked. The two paramedics went around the house to the back door. The back door was open, and as they removed the curtain that hung from the door, they found the patient with an air rifle pointing at them. The patient did, however, lower the weapon and one of the paramedics placed it farther away. The patient was easily excitable all the time, but he stayed at home and promised to take a taxi to the health centre.

Sometimes a patient's aggression may be associated with fear and he may be unable to understand why he is being approached by the emergency care staff. Patients, who suffer from delusions, confusion or dementia, may experience the staff as threatening and resort to physical aggression. A bite from a violent patient, for example, can lead to dangerous and persistent infections. The manner in which patients are approached and the situation managed is of great consequence.

The man was waving a stick and tried to attack us when we went to see him. The spectacles of one of the paramedics fell on the floor, but there were no serious injuries or bruises. The patient had dementia and he thought we were there to take him to prison.

An aged man started to hit and flail his arms about and tried to kick me when I took his vitals and listened to his breathing. He bit me in my right arm.

Risk factors related to the context: Emergency care professionals work in a variety of contexts, in and outdoors.

Limited space can increase risks, for example when care must be provided in confined spaces, such as toilets. Lack of exit paths can escalate the risk in violent situations. In addition, and importantly, very often care is provided in a moving ambulance. Each situation is unique and it may be difficult to anticipate the risks. The examples below demonstrate risks caused by weather conditions and pets.

The patient was lying on his back on ice. I tried to get to him as fast as possible and slipped. I hit my head on the ice but was able to continue immediately towards to patient.

I was about to enter a patient's home with my colleague. There was an angry dog in the yard. The dog bit my colleague's trousers' legs but did not cause any physical injury. We asked a family member to remove the dog. When I had the patient on a stretcher and was lifting him into the vehicle, the dog reached out from the family member's arms and bit me in my right arm. I got a wound.

Risk factors related to equipment: In emergency care providers' work, malfunctioning equipment and lack of experience can result in physical harm. A degree of technical skills and concentration are required to use the equipment safely. The professional's distress or anxiety will jeopardize both staff and patient safety.

While taking a patient out of the ambulance, the front legs of the stretcher did not catch normally. I had to make a sudden motion down and forward. After the event, my lower back became painful and I had difficulty moving.
My colleague somehow lifted the stretcher carelessly and the patient tilted and nearly fell off the stretcher. I made a sudden motion and caught the patient in my arms. I pulled my back and got a pain in my hip.

Risk factors related to emergency driving: It may prove challenging to provide effective care in a fast moving ambulance that has to overtake other vehicles. Other drivers' unexpected reactions may lead to sudden braking, as in the following example.

I was with my colleague, attending to a patient in the care compartment. The driver was a first responder. The driver suddenly slowed down from $140 \mathrm{kph}$. We have to remove our seatbelts every once in a while to care for the patient. Now I had stood up to care for the patient. I was holding on to the security rail, but still lost my grip because of the sudden braking. I rolled over, falling on my knees on an open emergency bag.

\section{Discussion}

Safety is an essential quality factor in emergency care $[4,33,34]$. Safety incidents and near misses in patient and occupational safety can be assessed in relation to the structure and process of the care [28]. In emergency care, structural factors involve the staff's competence structure and the context in which they work. Process factors, on the other hand, represent more individual factors present during the time continuum that starts with the first contact to the patient and ends with turning him over to follow-up care.

In this study, risks to patient safety were associated with the patient's psychological and physical status, medication, care equipment and context. Some of these factors can be anticipated and prevented by making use of relevant research results, whereas others are situation-specific and appear more randomly and unexpectedly. As they are difficult to predict, the risk of human error is increased. One can discern a chain of risks underpinning various safety incidents, which often has its onset in a relatively minor mistake in the assessment or interpretation of a situation. Fortunately, situation sensitivity is a skill that can be developed $[14,18]$.

One way to decrease medication errors, safety incidents and near misses is to provide continuing education, for example on pharmacology. Previous studies, too, stress the importance of further training and education to develop staff skills and knowledge $[6,8]$. Care equipment must be of high quality and it should be tested at the beginning of each shift. The importance of maintaining high quality in emergency care equipment has been observed before [10,11].

In this study, risks to occupational safety were associated with the patient's mental ill-being and aggression and with the context, care equipment and emergency driving. Safe and high quality equipment can decrease risks [11], as can continuing education.

\section{Conclusions}

This study analysed 45 incident descriptions accrued during 10 months in a hospital district that serves 200,000 inhabitants. The limited number of the descriptions can regarded as a limitation of the study, and longer data collection periods are indicated in similar studies in the future. On the other hand, this was a qualitative study, whose purpose was not to reach any quantitative generalizations. The credibility of the study, as one of the reliability criteria for qualitative research [34], is enhanced by the use of authentic extracts from the HaiPro System descriptions written by emergency care staff. 
The fact that only 45 incidents were reported in the anonymous online system can be considered a positive phenomenon, although it is most likely that many incidents, especially minor ones, are never reported. This point to an important conclusion: Staff should be encouraged to use the reporting system as an essential part of quality management in emergency services. Secondly, it can be inferred that more attention needs to be paid to assessing the overall emergency situation from the viewpoint of safety and to looking into the level and reliability of information before starting any diagnostic procedures and treatment.

The results are useful from the perspectives of patient and occupational safety. The knowledge can be applied in health care education, both during vocational qualification studies for emergency care staff or during first-cycle nursing studies and later, in various continuing education programs. Studying descriptions of staff experiences and near misses can make students better prepared for demanding acute situations.

\section{References}

1. Cure L, Zayas-Castro J, Fabri P (2011) Clustering-based methodology for analyzing near-miss reports and identifying risks in healthcare delivery. J Biomed Inform 44: 738-748.

2. Currie LM, Desjardins KS, Stone PW, Lai TY, Schwartz E, et al. (2007) Near-miss and hazard reporting: promoting mindfulness in patient safety education. Stud Health Technol Inform 129: 285-290.

3. Doupi P (2009) National reporting systems for patient safety incidents: a review of the situation in Europe. Helsinki: National Institute for Health and Welfare.

4. Glickman SW, Schulman KA, Peterson ED, Hocker MB, Cairns CB (2008) Evidence-based perspectives on pay for performance and quality of patient care and outcomes in emergency medicine. Ann Emerg Med 51: 622-631.

5. Mason S, O'Keeffe C, Coleman P, Edlin R, Nicholl J (2007) Effectiveness of emergency care practitioners working within existing emergency service models of care. Emerg Med J 24: 239-243.

6. Mason S, Knowles E, Freeman J, Snooks H (2008) Safety of paramedics with extended skills. Acad Emerg Med 15: 607-612.

7. Shaw R, Drever F, Hughes H, Osborn S, Williams S (2005) Adverse events and near miss reporting in the NHS. Qual Saf Health Care 14: 279-283.

8. Ebright PR, Urden L, Patterson E, Chalko B (2004) Themes surrounding novice nurse near-miss and adverse-event situations. J Nurs Adm 34: 531-538.

9. Force MV, Deering L, Hubbe J, Andersen M, Hagemann B, et al. (2006) Effective strategies to increase reporting of medication errors in hospitals. J Nurs Adm 36: 34-41.

10. Fournier M, Chenaitia H, Masson C, Michelet P, Behr M, et al. (2013) Crew and patient safety in ambulances: results of a personnel survey and experimental side impact crash test. Prehosp Disaster Med 28: 370-375.

11. Ludwig G (2013) Ambulance safety. Seeking a system to analyze \& prevent emergency vehicle crashes. JEMS 38: 24.

12. Marshall J, Lee YT (2012) A study on safety: highlights from workshop on ambulance patient compartments. JEMS 37: 52-54, 56, 58-9.

13. Axley L (2008) Competency: a concept analysis. Nurs Forum 43: 214-222.

14. Duff B (2013) Creating a culture of safety by coaching clinicians to competence. Nurse Educ Today 33: 1108-1111.
15. Girot EA (2000) Graduate nurses: critical thinkers or better decision makers? J Adv Nurs 31: 288-297.

16. Hains IM, Marks A, Georgiou A, Westbrook JI (2011) Non-emergency patient transport: what are the quality and safety issues? A systematic review. Int J Qual Health Care 23: 68-75.

17. O'Hara R, O'Keeffe C, Mason S, Coster JE, Hutchinson A (2012) Quality and safety of care provided by emergency care practitioners. Emerg Med J 29: 327-332.

18. Pointer JE, Levitt MA, Young JC, Promes SB, Messana BJ, et al. (2001) Can paramedics using guidelines accurately triage patients? Ann Emerg Med 38: 268-277.

19. Schmidt T, Atcheson R, Federiuk C, Mann NC, Pinney T, et al. (2000) Evaluation of protocols allowing emergency medical technicians to determine need for treatment and transport. Acad Emerg Med 7: 663-669.

20. Staff T, Sovik S (2011) A retrospective quality assessment of pre-hospital emergency medical documentation in motor vehicle accidents in southeastern Norway. Scand J Trauma Resusc Emerg Med 31: 20: 1-11.

21. Ebright PR, Patterson ES, Chalko BA, Render ML (2003) Understanding the complexity of registered nurse work in acute care settings. J Nurs Adm 33: 630-638.

22. Aston E, Young T (2009) Enhancing the reporting of "near miss" events in a children's emergency department. J Emerg Nurs 35: 451-452.

23. Hendel SA, Flanagan BT (2009) Communication failure in the intensive care unit--learning from a near miss. Anaesth Intensive Care 37: 847-850.

24. Reason J (2004) Beyond the organisational accident: the need for "error wisdom" on the frontline. Qual Saf Health Care 13 Suppl 2: ii28-33.

25. Handel DA, Wears RL, Nathanson LA, Pines JM (2011) Using information technology to improve the quality and safety of emergency care. Acad Emerg Med 18: e45-51.

26. Currie LM, Desjardins KS, Levine ES, Stone PW, Schnall R, et al. (2009) Web-based hazard and near-miss reporting as part of a patient safety curriculum. J Nurs Educ 48: 669-677.

27. Kelly JJ, Thallner E, Broida RI, Cheung D, Meisl H, et al. (2010) Emergency medicine quality improvement and patient safety curriculum. Acad Emerg Med 17 Suppl 2: e110-129.

28. Liu SW, Singer SJ, Sun BC, Camargo Jr CA (2011) A Conceptual model for assessing quality of care for patients boarding in the emergency department. Structure-process-outcome. Acad Emerg Med 18: 430-5.

29. 2008, Sosiaali- ja terveysministerio [Ministry of Social Affairs and Health]. Terveydenhuollon vaaratapahtumien raportointijarjestelmien kayttoonotto. [Introduction of a reporting system for dangerous situations in health care]. Helsinki.

30. Svartdal F (2011) The reward value of near-miss situations. Scand J Psychol 52: 209-217.

31. Kelly J, Wears R, Weir B; Society for Academic Emergency Medicine (2005) The Society for Academic Emergency Medicine position on principles for measuring quality and reporting incidents and adverse events. Acad Emerg Med 12: 1010.

32. Polit DF, Beck CT (2004) Nursing research. Principles and methods. Philadelphia: Lippincott Williams \& Wilkins.

33. Ironside PM, Sitterding M (2009) Embedding quality and safety competencies in nursing education. J Nurs Educ 48: 659-660.

34. Kylma J, Pelkonen M, Hakulinen T (2004) Laadullinen tutkimus ja nayttoon perustuva hoitotyo [Qualitative research and evidence-based nursing]. Hoitotiede 16: 250-7. 